\title{
Scenario analysis of sustainable development of the world largest alluvial island with high urbanization rate: the socioeconomic development and environment protection
}

\author{
X. Ni ${ }^{1,2}$, J. Lu ${ }^{3 *}$, F.Q. Gao ${ }^{1}$, L. Lan ${ }^{1}$, C.L. Pan ${ }^{1}$, Y.Q. Wu ${ }^{2}$ \\ ${ }^{1}$ Shanghai Water Information Center, Jiangsu Road 358, Shanghai 200050, PR CHINA \\ ${ }^{2}$ School of Environmental Science and Engineering, Shanghai Jiao Tong University, Dongchuan Road 800, Shanghai 200240, PR CHINA \\ $3^{*}$ School of Civil and Environmental Engineering, Georgia Institute of Technology, Atlanta, Georgia 30332, USA \\ "Corresponding Author: e-mail: lujian.leonard@gmail.com (Jian Lu)
}

\begin{abstract}
In this study, scenario analysis of the social development and environmental protection of Chongming Island, Shanghai, China, was performed to discuss the sustainable development of this special area. In this way, various system components including society, economy, ecology, environment and water resources system were all incorporated into this model framework for holistic consideration and optimization. According to the model output, the urbanization and environmental protection in Chongming Island will become more and more serious in 2020. Scenario 2 is obviously more preferable though its ecological goal is not the most satisfactory. Overall, Scenario 2 is finally deemed to be the most desirable plan. This study suggests that the Multi-objective Water Resource Carrying Capacity (MWRCC) model is a powerful decision tool for sustainable development assessment in region scale.
\end{abstract}

Keywords: Multi-objective, Chongming Island, Scenario analysis

\section{Introduction}

Chongming Island located north of Shanghai city and west of the East China Sea at the mouth of Yangtze River, is not only the largest alluvial island in the world but also the third largest island in China. At present, the "Ecological Island" project for Chongming Island has become important parts of ecological economy and sustainable development in China (Yuan et al., 2003). In this project, the sustainable development in the social development and environment protection is of the most importance. To achieve sustainability of this island, scenario analysis on the social sustainability and environment protection based on different development strategies is necessary before making related development decision.

Scenario analysis is one idea that scenario-building does not focus on making predictions, but rather on describing images of the future that challenge current assumptions and broaden perspectives. Scenarios analysis is highly applicable to mid-and-long range (10 years or more) futures studies where there are considerable levels of both predictability and uncertainty. For example, a systematic scenario process in the context of local sustainability planning was outlined in Ireland (Kelly et al., 2004). At a regional level, scenario analysis was used in planning for sustainability in the Willamette Basin of Oregon (Baker et al., 2002). At the global scale, scenarios were central elements of the Millennium Ecosystem Assessment (MA) for exploring changes in ecosystem services and their influences on human well-being (Carpenter et al., 2006). This study developed a modeling framework combining multi-objective analysis and multi-criteria decision methods to perform scenario analysis in dealing with the complexities of conflict resolution involved in local sustainable development planning of Chongming Island. The final purpose of this study is to find a suitable development mode of the Chongming Island according to the needs of sustainable development in Chongming Island. 


\section{Method}

2.1 Study area: Chongming Island is located north of shanghai in the lower Yangtze Estuary, which is between $121^{\circ} 09^{\prime}-121^{\circ} 54^{\prime} \mathrm{E}$ and $31^{\circ} 27^{\prime}-31^{\circ} 51^{\prime} \mathrm{N}$. It is $1,200 \mathrm{~km}^{2}$ in area and creasing in size by about 500 ha annually through the deposition of sand, silt, and mud by the Yangtze River. It is also the third largest island in China and the largest alluvial island in the world, which supported a population of about 635,000 people in 2005 . The special geographic location of this island makes it possible to maintain a high level of environmental quality. Therefore, it was developed into one national ecological area.

The topographical feature of the island is characterized by their relative elevations with high in the north and east, low in the west and south (3.2-4.5 m). The mean annual precipitation is $1049.3 \mathrm{~mm} ; 61.9 \%$ of the total year precipitation occurs during MaySeptember with the maximum precipitation of $160.3 \mathrm{~mm} / \mathrm{d}$ (happened in Jan 31st, 1977). The potential annual evaporation is 718.0 $\mathrm{mm}$; annual mean air temperature is $15.3{ }^{\circ} \mathrm{C}$, with the maximum and minimum of $21.3{ }^{\circ} \mathrm{C}$ and $12.9{ }^{\circ} \mathrm{C}$, respectively. The fundamental features of society and economy (Table 1) in the study region can be summarized from local statistics agency as follows:

Table 1. Fundamental feature of society and economy on Chongming Island

\begin{tabular}{|c|c|c|c|c|c|c|c|}
\hline Year & $\begin{array}{c}\text { Population } \\
\left(\times 10^{4}\right)\end{array}$ & $\begin{array}{c}\text { Urban } \\
\text { population } \\
\left(\times 10^{4}\right)\end{array}$ & $\begin{array}{c}\text { Irrigation } \\
\text { area } \\
\left(\times 10^{4} \text { ha) }\right.\end{array}$ & $\begin{array}{c}\text { GDP of } \\
\text { agriculture } \\
(\text { Billion Yuan } \\
\text { RMB) }\end{array}$ & $\begin{array}{c}\text { GDP of } \\
\text { industry } \\
\text { (Billion } \\
\text { Yuan RMB) }\end{array}$ & $\begin{array}{c}\text { GDP of } \\
\text { Service industry } \\
(\text { Billion } \\
\text { Yuan RMB) }\end{array}$ & $\begin{array}{c}\text { Personal income } \\
\text { per capita } \\
(\text { Yuan RMB) }\end{array}$ \\
\hline 1995 & 71.30 & 11.57 & 44.5 & 9.83 & 14.89 & 9.58 & 10287 \\
\hline 2000 & 65.37 & 12.07 & 44.2 & 13.39 & 20.21 & 20.38 & 11458 \\
\hline 2005 & 63.26 & 15.30 & 43.7 & 14.95 & 34.57 & 29.47 & 17320 \\
\hline
\end{tabular}

2.2 Data acquisition: The original data was obtained from the local official agency and Statistic yearbook of Chongming. Furthermore, several field surveys were made since 2005. However a few data sets are patchy, incomplete, they were solved by means of interpolation and prolonging data.

2.3 Scenario design and analysis: Scenario development as an aid to planning is focused on developing alternative visions of the future. It has been proven to be a disciplined method for imagining possible futures in which decisions may be played out, and a powerful tool for asking "what if" questions to explore the consequences of uncertainty (Koch et al., 2005; Duinker and Greig, 2007). In this study, the scenarios of the future related to MWRCC were simplified into four subsystems for special analysis: human population, economy development, water resources exploitation, and ecology and agriculture. The planning year of scenario analysis is 2010,2015 , and 2020.

2.3.1 Population and urbanization level: Since 1995, the number of permanent residents living on Chongming Island has been declining, with an average natural growth rate of $-3.1 \%$, which is much lower than the average national level of $7.5 \%$, but the number of temporary residents has been growing rapidly, at an average growth rate of $4.2 \%$. The natural growth rate is likely to start stabilizing in the next ten years. However, the temporary population's rapid growth phase is bound to appear because of the implementation of national "Ecological Island" project and the construction of the Yangtze Bridge, completed for the 2010 Shanghai International Fair. A great number of workers, scientists, and technicians will be attracted to Chongming. In 2005, there were about 0.63 million residents living in the island, of which 0.56 million residents were living in the rural areas. It showed a low urbanization level now, but more and more residents living in the rural district will be moved to the town by the government.

In this scenario analysis, classical Exponential Growth model, Thrice Exponential Mean Sliding model, and Grey Relation Theory were used to predict the population. Then, two scenarios were identified; one addressed the concerns of population growth and urbanization development with low speed, the other with high speed. The scenarios values were given in Table 2 .

Table 2. Scenario values of population and urbanization level on Chongming Island

\begin{tabular}{|c|c|c|c|c|c|c|}
\hline Year & \multicolumn{2}{|c|}{2010} & \multicolumn{2}{c|}{2015} & \multicolumn{2}{c|}{2020} \\
\hline Scenarios & Low & High & Low & High & Low & High \\
\hline Population $\left(\times 10^{4}\right)$ & 74.62 & 77.73 & 82.08 & 85.50 & 88.64 & 92.32 \\
\hline Urban population $\left(\times 10^{4}\right)$ & 26.12 & 35.98 & 38.58 & 43.61 & 50.52 & 57.25 \\
\hline Urbanization level $(\%)$ & 35 & 45 & 47 & 51 & 57 & 62 \\
\hline
\end{tabular}

2.3.2 Economy development: In this section, Chinese Macroeconomic Meterage model-project link (1997 edition) was adopted. But, some modules were modified. Firstly, six primary production departments (agriculture, industry, architecture, commerce, 
transportation service, and post and telecommunication industry) in the project link model were adjusted to four production departments (agriculture, industry, architecture industry and service industry). Secondly, the population and labor force module was modified to population scenarios previously analyzed. Thirdly, hydraulic engineering investment, sewage treatment investment and ecology construction investment were added into the fixed assets investment module as analysis condition of policy scenarios.

Chongming Island will face with an important transformation period of economy structure in the next ten years. The investment rate can be set from $35 \%$ to $45 \%$. The investment rate may present itself with declining tendency ten years later. The investment rate can be set from $25 \%$ to $35 \%$. Economy growth with high and low speed because of different fixed assets investment rate was set as Scenario $A_{1}$ and Scenario $A_{2}$ respectively. The scenario values of the economy growth rate in percent per year on Chongming Island were given in Table 3.

Table 3. Scenario values of the economy growth rate in percent per year on Chongming Island

\begin{tabular}{|c|c|c|c|c|c|c|}
\hline Year & \multicolumn{2}{|c|}{2010} & \multicolumn{2}{c|}{2015} & \multicolumn{2}{c|}{2020} \\
\hline Scenarios & $\mathrm{A}_{1}$ & $\mathrm{~A}_{2}$ & $\mathrm{~A}_{1}$ & $\mathrm{~A}_{2}$ & $\mathrm{~A}_{1}$ & $\mathrm{~A}_{2}$ \\
\hline Primary industry (\%) & 6.31 & 5.40 & 5.10 & 4.60 & 4.38 & 4.16 \\
\hline Secondary industry (\%) & 21.00 & 18.25 & 17.12 & 15.67 & 14.68 & 13.56 \\
\hline Service industry (\%) & 14.25 & 12.30 & 11.61 & 10.56 & 9.96 & 9.54 \\
\hline Total growth (\%) & 16.16 & 14.03 & 13.17 & 12.04 & 10.30 & 9.80 \\
\hline
\end{tabular}

2.3.3 Water resources exploitation: At present, Chongming has two water sources. One is Nanheng River on Chongming Island, the other is Yangtze River. The annual water resources volume are $35.37 \times 10^{8} \mathrm{~m}^{3}, 33.60 \times 10^{8} \mathrm{~m}^{3}, 32.15 \times 10^{8} \mathrm{~m}^{3}$, and $31.05 \times 10^{8} \mathrm{~m}^{3}$ given different guaranteed efficiency ( $\mathrm{P}=20 \%, 50 \%, 75 \%, 90 \%)$. Among them, the water resources volume from Yangtze River is $31.92 \times 10^{8} \mathrm{~m}^{3}, 30.15 \times 10^{8} \mathrm{~m}^{3}, 28.70 \times 10^{8} \mathrm{~m}^{3}$, and $27.60 \times 10^{8} \mathrm{~m}^{3}$ respectively. The water quality is classified as category IV according to Chinese government standard for water quality issued in 2002 (GB3838-2002). According to water resources plan of Chongming Island, four new water supply plants will have been completed by 2010, which will increase the water supply volume about $36 \times 10^{4} \mathrm{~m}^{3} /$ day. Moreover, four new sewage plants will be completed by 2010 in order to change the situation of no sewage plant on this island. Furthermore, the sewage plants can be able to deal with $8.5 \times 10^{4} \mathrm{~m}^{3}$ sewage and industrial waste water each day.

In this section, scenario analysis is mainly composed of available water resources and water use quota. Water supply at a reasonable growth speed and in a reasonable expanding scale can be accomplished when water conservancy accounts about $1.2 \%$ of the GDP. Therefore, the high $\left(\mathrm{B}_{1}\right)$ and low $\left(\mathrm{B}_{2}\right)$ water conservancy investment's ratios were set as $2 \%$ and $1 \%$, in which water supply investment ratio was set $1.0 \%$ and $0.5 \%$, water savings' investment ratio was set $0.7 \%$ and $0.4 \%$, and water sewage dealing engineering investment ratios was set as $0.3 \%$ and $0.1 \%$. According to related survey, the water resources investment on water supply engineering, agricultural saving-water engineering, industrial saving-water engineering and sewage dealing engineering costs about 3.82, 3.12, 2.75 and $5.50 \mathrm{Yuan} \mathrm{RMB} / \mathrm{m}^{3}$ respectively. With respect to scenario value of economic development and the related water resources report, the total available water resources on Chongming Island under the guaranteed efficiency of $75 \%$ was estimated. These values were shown in Table 4.

Table 4. Water use quota from 2010 to 2020 on Chongming Island

\begin{tabular}{|c|c|c|c|c|c|c|}
\hline Year & \multicolumn{2}{|c|}{2010} & \multicolumn{2}{c|}{2015} & \multicolumn{2}{c|}{2020} \\
\hline Scenarios & $\mathrm{B}_{1}$ & $\mathrm{~B}_{2}$ & $\mathrm{~B}_{1}$ & $\mathrm{~B}_{2}$ & $\mathrm{~B}_{1}$ & $\mathrm{~B}_{2}$ \\
\hline Available water supply $\left(10^{8} \mathrm{~m}^{3}\right)$ & 9.58 & 6.99 & 10.55 & 7.39 & 11.80 & 7.89 \\
\hline Water use volume of unit GDP $\left(\mathrm{m}^{3} / 10^{4}\right.$ Yuan $\left.\mathrm{RMB}\right)$ & 355 & 365 & 210 & 215 & 117 & 123 \\
\hline Industrial water use quota $\left(\mathrm{m}^{3} / 10^{4}\right.$ Yuan RMB) & 47 & 49 & 41 & 44 & 36 & 40 \\
\hline Agricultural irrigation quota $\left(\mathrm{m}^{3} /\right.$ hectare) & 26.8 & 28.3 & 24.6 & 25.9 & 22.7 & 23.8 \\
\hline Domestic water quota in town $(1 /$ day-person) & 192 & 200 & 241 & 247 & 260 & 280 \\
\hline Domestic water quota in rural district (1/day-person) & 138 & 156 & 167 & 179 & 200 & 220 \\
\hline Comprehensive domestic water quota (1/day-person) & 159 & 168 & 203 & 229 & 235 & 254 \\
\hline
\end{tabular}

The water use quota is affected by four factors including local scientific and technological level, industry structure, natural conditions, and water resources management level. On the basis of influencing factors as well as its changing rule, there are mainly three estimation methods such as tendency method, scenario analysis, and empiric formula. In this study, the first method is 
adopted. The concrete consumption quota indexes (Table 4) we estimated were water use volume of unit GDP, industrial water use quota, agricultural irrigation quota, and domestic water quota.

2.3.4 Ecology and agriculture: Ecological and environmental quality is the key symbol for the "Ecological Island" development, which depends on the support of water resources to a great extent. Based on statistical analysis of historical water utilization data, agricultural irrigation is the highest water consumer. This section includes scenarios of forest and grass area, ecology and environment water requirement volume, and agricultural irrigation area.

The total area of forest and grass in 2005 on Chongming Island was $1.76 \times 10^{4}$ ha, accounting for $16.8 \%$ of the total island area. According to the standard of national ecology demonstration district, $2.43 \times 10^{4}$ ha forest and grass area needs to increase. The increased area of forest and grass in high scenario $\left(\mathrm{C}_{2}\right)$ and low scenario $\left(\mathrm{C}_{1}\right)$ in different plan year were given in Table 5 .

Ecology and environment water requirement volume has relation to many aspects such as local rainfall and plants. But it has characteristic in estuary districts. Here, its computation was simplified (ecology and environment water requirement volume =surface runoff volume + actual water resources volume from Yangtze River - national economic water use volume). In fact, the value is very stable in each scenario in Chongming. It is about $5.32 \times 10^{8} \mathrm{~m}^{3}$.

Table 5. Environment and agriculture scenarios on Chongming Island

\begin{tabular}{|c|c|c|c|c|c|c|}
\hline Year & \multicolumn{2}{|c|}{2010} & \multicolumn{2}{c|}{2015} & \multicolumn{2}{c|}{2020} \\
\hline Scenarios & $\mathrm{C}_{1}$ & $\mathrm{C}_{2}$ & $\mathrm{C}_{1}$ & $\mathrm{C}_{2}$ & $\mathrm{C}_{1}$ & $\mathrm{C}_{2}$ \\
\hline Forest and grass area $\left(\times 10^{4} \mathrm{ha}\right)$ & 2.49 & 2.78 & 3.03 & 3.56 & 3.72 & 4.57 \\
\hline
\end{tabular}

2.3.5 Scenarios combination: Based on the above scenario analysis in the aspect of economy development, water resources exploitation, and ecology and irrigation area, four scenarios combinations were identified in this study, they were $A_{1}+B_{1}+C_{1}$ (Scenario 1), $A_{1}+B_{1}+C_{2}$ (Scenario 2), $A_{2}+B_{2}+C_{1}$ (Scenario 3) and $A_{2}+B_{2}+C_{2}$ (Scenario 4). For example, Scenarioladdressed concern for economy development with high speed, high water resources exploitation level, low ecology and environmental protection level, and proper growth of irrigation area.

2.4 MWRCC model: The goal of the water resources carrying capacity optimized model is to promote the harmonious developments of economy, society, and environment. Based on the system analysis and sustainable development principle, a new MWRCC model for Chongming Island was developed (Harris and Kennedy, 1999; Cuadra and Bjorklund, 2006; Dvarioniene and Stasiskiene, 2007).

2.4.1 Objective function: This study has three objectives: maximum of GDP per capita, minimum of sewage discharge volume, and maximum of forest and gross area (Cai and Rosegrant 2005), which represents economy development extent, environment and ecology condition. Each detailed formulation follows.

$$
\left\{\begin{array}{l}
\operatorname{Max} f_{1}\left(x_{1}, x_{2}, x_{3}, x_{4}, x_{5}\right) \\
\operatorname{Min} f_{2}\left(x_{2}, x_{4}, x_{5}\right) \\
\operatorname{Max} f_{3}\left(x_{6}, x_{7}\right)
\end{array}\right.
$$

where $\mathrm{x}_{1}, \mathrm{x}_{2}, \mathrm{x}_{3}$ is the GDP of primary industry, secondary industry and service industry; $\mathrm{x}_{4}$ is the population; $\mathrm{x}_{5}$ is the urbanization level; $\mathrm{x}_{6}, \mathrm{x}_{7}$ is the forest and grass area.

2.4.2 Constraints: In the MWRCC model for Chongming Island, the objective functions are subject to four constraints. They are water resources balance between water supply and water demand, soc-economic development speed and its structure balance, ecology protection, and non-negativity which are expressed by the followed equations.

\section{A. Water resources balance between water supply and water demand constraint}

$$
\left\{\begin{array}{l}
W_{D}=\phi\left(\bar{W}_{R}, \bar{W}_{U}, \bar{W}_{W}, \bar{W}_{I}, x_{1}, x_{2}, x_{3}, x_{4}\right) \leq W_{S} \\
W_{G}=\phi\left(S_{I}, \bar{W}_{G}\right) \leq W_{A} \\
W_{D}+W_{E} \leq W_{T}
\end{array}\right.
$$

where $W_{D}$ is the whole water demand of national economy; $W_{S}$ is the maximum water resources available; $W_{G}$ is the irrigation water use volume; $\mathrm{W}_{\mathrm{A}}$ is the whole agricultural water use volume; $\mathrm{W}_{\mathrm{E}}$ is the ecology water demand; $\mathrm{W}_{\mathrm{T}}$ is the annual water 
resources volume; $\mathrm{S}_{\mathrm{I}}$ is the irrigation area; $\overline{\mathrm{W}}_{\mathrm{R}}$ is the domestic water use quota in rural district; $\overline{\mathrm{W}}_{\mathrm{U}}$ is the domestic water use quota in town; $\overline{\mathrm{W}}_{\mathrm{A}}$ is the agricultural water use quota; $\overline{\mathrm{W}}_{\mathrm{W}}$ is the water use quota of unit GDP; $\overline{\mathrm{W}}_{\mathrm{G}}$ is the irrigation water use quota.

B. Soc-economic development speed and its structure balance constraint

$$
\left\{\begin{array}{l}
r_{i}=\phi\left(x_{i}\right) \geq v_{i} \\
\delta=\phi\left(x_{4}\right) \leq u \\
\partial_{i}=\phi\left(x_{i}\right) \geq \theta_{i} \\
x_{5} \geq \rho
\end{array}\right.
$$

where $r_{i}(i=1,2,3)$ is the economic development speed of different industry; $\partial_{\mathrm{i}}(\mathrm{i}=1,2,3)$ is the proportion to the GDP of different industry; $\delta$ is the population growth rate; $v_{i}, \mathrm{u}, \theta_{\mathrm{i}}, \rho$ are the corresponding scenario values of population and economy development scenario analysis.

\section{Ecology and environment protection constraint}

$$
\left\{\begin{array}{l}
x_{6} \geq S_{l} \\
x_{7} \geq S_{c}
\end{array}\right.
$$

where $S_{l}$ is the planed forest area; $S_{c}$ is the planed gross area.

2.4.3 Solution techniques: Fifteen techniques in terms of 24 criteria were evaluated, forming an evaluation matrix of criteria versus alternative multi-objective decision making (MCDM) techniques (Tecle, 1992). In that study, the compromise programming, based on scaling of the outcome for each criterion and subsequently calculating a weighed sum of the metric distance for each criterion for making single objective function, is observed to be ranked first in solving various multi-objective water resources problems.

$$
\left\{\begin{array}{l}
\text { Minimize }: d_{p}=\left[\sum_{i=1}^{n} \lambda_{i}^{p}\left(\frac{f_{i}^{*}(x)-f_{i}(x)}{f_{i}^{*}(x)-f_{i}^{\prime}(x)}\right)^{p}\right]^{\frac{1}{p}} \\
1<p<\infty, \lambda_{i}^{p}>0 \\
\sum_{i=1}^{n} \lambda_{i}^{p}=1
\end{array}\right.
$$

where $\lambda_{\mathrm{i}}$ is the weight for criterion $i ; f_{i}^{*}(x)$ is the desired value of criterion $i ; f_{i}^{\prime}(x)$ is the worst value, $n$ is a parameter represents the total number of objectives, $p$ is the parameter defining the metric of $d_{p}$.

Value of $p$ referring to the distances from the ideal point is emphasized. For $p=1$, this problem becomes a liner program; while $p=2$, a simple squared distance is calculated; if $p \rightarrow \infty$, the largest deviation is considered. Different decision makers have various weights for each criterion. Linguistic weights for criteria were defined in this study. The set of weights and their numeric equivalents is as Eq. (6), which is based on works in Analytic Hierarchy Process (AHP) methods.

$$
\{\text { very low, low, medium, high, very high }\}=\{1,3,5,7,9\}
$$

\section{Results and discussion}

3.1 Urbanization and population: In the near future, the urbanization will also experience a rapid growth phase (Table 6). The urbanization level will grow to $65 \%$, which will exceed the urbanization level of the developed countries (63\%), by 2020 from $24 \%$ in 2005 under Scenario II. Under Scenario I, scenario III, and scenario IV, this level will be $63 \%, 59 \%, 60 \%$, respectively by 2020. It will exceed the urbanization average level (46\%) in the world, and will be close or equal to the urbanization level of the developed countries. The scenario analysis showed that there would be a rapid increase in the population number in Chongming Island. The population number will increase by about $40 \%$ at the end of 2020 . At that time, the population number will reach at 91.5, 92.1, 88.3 and $88.6 \times 10^{4}$ respectively under Scenario I, Scenario II, Scenario III and Scenario IV, respectively. The rapid increase potential in the population is not caused by the reproduction of the local people since the natural population growth rate is lower in Chongming than that of mean level in China. At present, the "Ecological Island" project for Chongming Island has been 
important parts of ecological economy and sustainable development in China (Yuan et al., 2003). The related attractive policy for work, the high environmental quality for habitation, low house price, and rapid urbanization, which can bring more convenience for the life of the people in developing country, will stimulate more and more people moving to this area from other. It is safe to argue that immigration will be the main reason for the rapid increase in the population.

Table 6. Population and urbanization of Chongming Island

\begin{tabular}{|c|c|c|c|}
\hline \multirow{3}{*}{ year } & Scenario & Urbanization (\%) & Population $\left(\times 10^{4}\right.$ person) \\
\hline 2005 & - & 24 & 63 \\
\hline \multirow{4}{*}{2010} & Scenario I & 46 & 77.4 \\
\cline { 2 - 4 } & Scenario II & 48 & 77.6 \\
\cline { 2 - 4 } & Scenario III & 36 & 74.3 \\
\cline { 2 - 4 } & Scenario IV & 37 & 74.4 \\
\hline \multirow{4}{*}{2015} & Scenario I & 53 & 84.7 \\
\cline { 2 - 4 } & Scenario II & 55 & 85.2 \\
\cline { 2 - 4 } & Scenario III & 48 & 81.7 \\
\cline { 2 - 4 } & Scenario IV & 50 & 81.9 \\
\hline \multirow{5}{*}{2020} & Scenario I & 63 & 91.5 \\
\cline { 2 - 4 } & Scenario II & 65 & 92.1 \\
\cline { 2 - 4 } & Scenario III & 59 & 88.3 \\
\cline { 2 - 4 } & Scenario IV & 60 & 88.6 \\
\hline
\end{tabular}

3.2 Macroeconomic gross and economy structure: According to the result of MWRCC model, under Scenario I, the annual economic growth rate is $16.4 \%, 13.5 \%$, and $10.4 \%$ in 2010,2015 and 2020 , respectively. The GDP on Chongming Island will be up to $1.89 \times 10^{4}, 3.56 \times 10^{4}$ and $5.84 \times 10^{4}$ million Yuan RMB by 2010, 2015 and 2020, respectively. The GDP will be twice in 2010 than that in $2005\left(0.89 \times 10^{4}\right.$ million), and it will reach six times in 2020 than that in 2005.The policy of "Ecological Island" development and the Yangtze River Bridge's completion by 2010 is a crucial driving force for the economic development. The GDP per capita will also be 24,419, 42,031 and 63,825 Yuan RMB by 2010, 2015 and 2020, which is much more than that in 2005 $(13,828$ Yuan RMB).The results under other three scenarios in 2010,2015 and 2020 are shown in Figure 1.

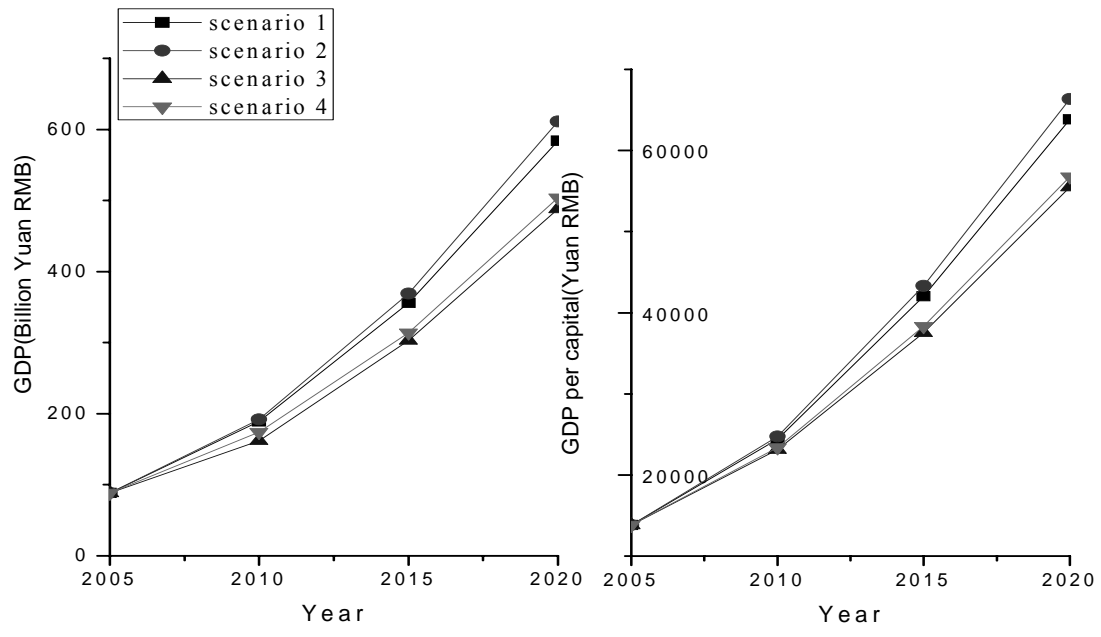

Figure 1 The GDP and GDP per capital on Chongming Island

The optimum economy structure is shown in Table 7. A clear economic development trend was shown by the model. The agricultural proportion to the GDP will decrease fast. On the opposite, the service industry proportion will expand rapidly. The industry proportion will change little. In 2005, agriculture, industry, service industry accounted for the GDP was $18.8 \%, 43.8 \%$ and $37.4 \%$ respectively. By 2020 , these percentages will change to $8.8 \%, 44.9 \%$ and $46.3 \%$ under Scenario I, $8.7 \%, 44.6 \%$ and 
$46.7 \%$ under Scenario II, 9.6\%, 45.1\% and 45.3\% under Scenario III, and 9.3\%, 44.8\% and $45.9 \%$ under Scenario IV. In the service industry, tourism of the Chongming Island will become a most powerful industry because of the good environmental quality.

Table 7. Proportion to GDP of different industry on Chongming Island

\begin{tabular}{|c|c|c|c|c|}
\hline Year & Scenario & Agriculture (\%) & Industry (\%) & Service production (\%) \\
\hline \multirow{4}{*}{2010} & Scenario I & 12.7 & 47.6 & 39.7 \\
\hline & Scenario II & 12.1 & 47.1 & 40.8 \\
\hline & Scenario III & 13.4 & 46.3 & 40.3 \\
\hline & Scenario IV & 12.5 & 45.9 & 41.6 \\
\hline \multirow{4}{*}{2015} & Scenario I & 9.7 & 47.2 & 43.1 \\
\hline & Scenario II & 9.5 & 46.8 & 43.7 \\
\hline & Scenario III & 10.4 & 47.7 & 41.9 \\
\hline & Scenario IV & 10.1 & 47.3 & 42.6 \\
\hline \multirow{4}{*}{2020} & Scenario I & 8.8 & 44.9 & 46.3 \\
\hline & Scenario II & 8.7 & 44.6 & 46.7 \\
\hline & Scenario III & 9.6 & 45.1 & 45.3 \\
\hline & Scenario IV & 9.3 & 44.8 & 45.9 \\
\hline
\end{tabular}

3.3 Environment protection: Forest and grass area will increase continually under all of the scenarios. By 2020, its coverage rate will be up to $44.2 \%$ and $44.7 \%$ from $16.8 \%$ in 2005 under Scenario III and Scenario IV respectively, which exceed the national ecology park standard (40\%). It can also grow to $35.8 \%$ and $36.0 \%$ under Scenario I and Scenario II, respectively. Furthermore, the coverage rate is smaller under former two scenarios than that of the latter two scenarios. The possible reason is that high speed economic development makes it easier to pollute the ecosystem.

\section{Conclusions}

This study demonstrated that MWRCC model can be a powerful tool to provide an important reference for the research on region sustainable development. Through the MWRCC model, four planning scenarios were presented and analyzed, providing necessary information for the decision maker in selecting the most desirable society-economy-ecology development mode for Chongming Island. On base of well ecology protection, the economic goal is considered the most important factor in the water resources sustainable development for developing countries. Scenario II is obviously more preferable though its ecological goal is not most satisfied. Overall, Scenario II is finally deemed to be the most desirable plan. It suggests the policy of economic development with rapid growth, better ecological and environmental protection and strictly control on irrigation area may achieve maximum social, economic and ecological and environmental benefits for Chongming Island in future. The service industry should be treated the most hopeful industry on Chongming Island and can promote the growth of other industries, in which tourism is bound to be the most important leading industry because of ecological island' reputation in future. Forest and grass coverage rate, food supplies safety and water use benefit can all reach a favorable level by 2020 under the optimal scenario.

\section{Acknowledgements}

This work is supported by a grant from the Key Programs of Science and Technology Commission Foundation of Shanghai Province (No. 05DZ12007-1) and a grant from Opening Research Fund of key laboratory of Urbanization and Ecological restoration in Shanghai. The authors are very grateful to the anonymous reviewers for reading the manuscript and providing suggestions.

\section{References}

Baker, J.P., Hulse, D.W., Gregory, S.V., White, D., Van Sickle, J., Berger, P.A., Dole, D. and Schumaker N.H. 2002. Alternative futures for the Willamette River Basin Oregon. Ecological Applications, Vol. 14, No. 2, pp. 313-324.

Cai, X.M. and Rosegrant, M.W. 2005. Water management and food production in China and India: a comparative assessment. Water Policy, Vol. 7, No. 6, pp. 643-663.

Carpenter, S.R., Bennett, E.M. and Peterson, G.D. 2006. Scenarios for ecosystem services: an overview. Ecology and Society, Vol. 11, No. 1, Art. 29. 
Cuadra, M. and Bjorklund, J. 2006. Assessment of economic and ecological carrying capacity of agricultural crops in Nicaragua. Ecological Indicators, Vol. 7, No. 1, pp. 133-149.

Duinker, P.N. and Greig, L.A. 2007. Scenario analysis in environmental impact assessment improving explorations of the future. Environmental Impact Assessment Review, Vol. 27, No. 3, pp. 206-219.

Dvarioniene, J. and Stasiskiene, Z. 2007. Integrated water resource management model for process industry in Lithunania. Journal of Cleaner Production, Vol. 15, pp. 950-957.

Harris, J. M. and Kennedy, S. 1999. Analysis carrying capacity in agriculture: global and regional issues. Ecological Economics, Vol. 29, pp. 443-461.

Kelly, R., Sirr, L. and Ratcliffe, J. 2004. Futures thinking to achieve sustainable development at local level in Ireland. Foresight, Vol. 6, No. 2, pp. 80-90.

Koch, H., Kaltofen, M., Grünewald, U., Messner, F., Karkuschke, M., Zwirner, O. and Schramm, M. 2005. Scenarios of water resources management in the Lower Lusatian mining district, Germany. Ecological Engineering, Vol. 24, No. 1, pp. 49-57.

Tecle, A. 1992. Selecting a multicriterion decision making technique for watershed resources management .Water Resources Bulletin, Vol. 28, No. 1, pp. 129-140.

Yuan, W., James, P., Hodgson, K., Hutchinson, S.M. and Shi, C. 2003. Development of sustainability indicators by communities in China: a case study of Chongming County, Shanghai. Journal of Environmental management, Vol. 68, No. 3, pp. 253-261.

\section{Biographical notes}

X. Ni is a Ph.D candidate from Shanghai Jiao Tong University, and he is an engineer in Shanghai Water Information Center, Shanghai, China. His current area of research includes Environmental Protection, Water Resources Management, Multi-criteria Decision-Making, and Non-traditional Optimization and Simulation. He has published several papers in referred international and national journals. He is currently dealing with a few projects sponsored by government of China.

J. Lu is currently a research engineer studying the transport and fate of hazardous pollutants in engineered bioremediation and natural systems at Georgia Institute of Technology. He graduated from Shanghai Jiao Tong University in 2008 and received his Ph. D degree in environmental engineering. He focuses his research interests on the biodegradation or biotransformation behaviors of hazardous pollutants and related treatment techniques for water, air \& soil pollution. Research on environment sustainability and bio-energy technology such as microbial fuel cell technique is also included.

F.Q. Gao received Ph.D. from East China Normal University, China in 2005. Presently she works in Shanghai Water Information Center. Her research interests include Geology Information System, Water Resources Protection and Environmental Planning. She has published more than ten papers in national journals and conferences.

L. Lan is an engineer in Shanghai Water Information Center, Shanghai, China. She has more than eight years experience of water resources planning and protection. Her research interests include Water Resources Protection and Ocean Environmental Protection.

C.L. Pan is an engineer in Shanghai Water Information Center, Shanghai, China. He received Master degree in 2005. His research interests include Water Resources Planning, Computer System Restructuring, Computer System Optimization \& Control and Environmental Protection.

Y.Q. Wu is a Professor in School of Environmental Science and Engineering, Shanghai Jiaotong University, China. His research interests include Ecology Protection, Environmental System Simulation, Water Resources Management and Geotechnical Engineering. He has published more than one hundred and seventy papers in referred international and national journals.

Received January 2010

Accepted April 2010

Final acceptance in revised form September 2010 